\title{
A deeper investigation of different types of core users and their contributions for sustainable innovation in a company-hosted online co- creation community
}

Yu Wang, Cheng Li, Dongsong Zhang, Jiacong Wu and Yang Liu

The self-archived postprint version of this journal article is available at Linköping University Institutional Repository (DiVA):

http://urn.kb.se/resolve?urn=urn:nbn:se:liu:diva-165465

N.B.: When citing this work, cite the original publication.

Wang, Yu, Li, C., Zhang, D., Wu, J., Liu, Y., (2020), A deeper investigation of different types of core users and their contributions for sustainable innovation in a company-hosted online co-creation community, Journal of Cleaner Production, 256, 120397.

https://doi.org/10.1016/j.jclepro.2020.120397

Original publication available at:

https://doi.org/10.1016/j.jclepro.2020.120397

Copyright: Elsevier

http://www.elsevier.com/

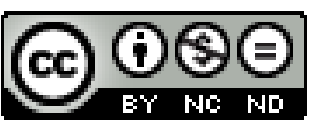




\section{Journal Pre-proof}

A deeper investigation of different types of core users and their contributions for sustainable innovation in a company-hosted online co-creation community

Yu Wang, Cheng Li, Dongsong Zhang, Jiacong Wu, Yang Liu

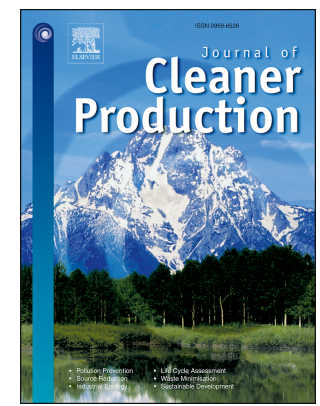

PII: S0959-6526(20)30444-3

DOI: https://doi.org/10.1016/j.jclepro.2020.120397

Reference: JCLP 120397

To appear in: Journal of Cleaner Production

Received Date: 13 July 2019

Revised Date: 14 January 2020

Accepted Date: 2 February 2020

Please cite this article as: Wang Y, Li C, Zhang D, Wu J, Liu Y, A deeper investigation of different types of core users and their contributions for sustainable innovation in a company-hosted online co-creation community, Journal of Cleaner Production (2020), doi: https://doi.org/10.1016/ j.jclepro.2020.120397.

This is a PDF file of an article that has undergone enhancements after acceptance, such as the addition of a cover page and metadata, and formatting for readability, but it is not yet the definitive version of record. This version will undergo additional copyediting, typesetting and review before it is published in its final form, but we are providing this version to give early visibility of the article. Please note that, during the production process, errors may be discovered which could affect the content, and all legal disclaimers that apply to the journal pertain.

(C) 2020 Published by Elsevier Ltd. 


\section{CRediT author statement}

Wang Yu: Conceptualization, Supervision Cheng Li: Methodology, Software, Investigation, Writing- Original draft preparation. Dongsong Zhang: Writing Original Draft, Validation, Writing- Reviewing and Editing Jiacong Wu: Data curation Yang Liu: Writing- Reviewing and Editing. 
A deeper investigation of different types of core users and their contributions for sustainable innovation in a company-hosted online co-creation community Yu Wang ${ }^{\mathrm{a}, \mathrm{b}}$, Cheng Li ${ }^{\mathrm{a}, \mathrm{b}^{*}}$, Dongsong Zhang ${ }^{\mathrm{a}, \mathrm{c}}$, Jiacong $\mathrm{Wu}^{\mathrm{a}, \mathrm{b}}$, Yang Liu ${ }^{\mathrm{d}, \mathrm{e}^{*}}$ ${ }^{a}$ School of International Business, Jinan University (Zhuhai Campus), Zhuhai, 519070, China; twygs@jnu.edu.cn (Y.W.);lcqd@stu2018.jnu.edu.cn; dzhang15@uncc.edu skywu@stu2017.jnu.edu.cn

${ }^{\mathrm{b}}$ Institute of Management Science and Engineering, Jinan University (Zhuhai Campus), Zhuhai, 519070, China

${ }^{\mathrm{c}}$ Belk College of Business University of North Carolina at Charlotte, 9201 University City Blvd, Charlotte, NC 28223-0001

${ }^{d}$ Department of Management and Engineering, Linköping University, SE-581 83 Linköping, Sweden

${ }^{e}$ Department of Production, University of Vaasa, 65200 Vaasa, Finland

*Correspondence: lcqd@stu2018.jnu.edu.cn; yang.liu@liu.se; 


\section{A deeper investigation of different types of core users and their contributions for sustainable innovation in a company-hosted online co-creation community}

Abstract: Online co-creation allows companies to leverage external sources of knowledge to sustain product or service innovation. Users' knowledge is regarded as such a potential source. Understanding user behaviors and innovation types is vital to improving a company's sustainable innovation. Many prior studies mainly categorized online community members into core and peripheral members based on their posting frequencies. However, little research has gone beyond that categorization and examined whether there may be different types of core members who may contribute to product or service innovation differently, especially in the context of co-creation. The objectives of this study are three-fold: (1) to identify core members of a company-hosted online co-creation community automatically by considering several dimensions of individual members, including posting behavior, the generated content, and social network features; (2) to categorize and compare the contributions of different types of core members in the community, aiming to identify community members who may play leadership roles in sustainable innovation; and (3) to investigate the influence of those different types of core members on other community members. The data collected from a company-hosted online co-creation community in China were analyzed. Through analysis, we developed a novel innovation-oriented topology of core community members consisting of eight types. Based on Practice Theory, we also explored how those different types of core community members may influence other members' behavior. Finally, based on the findings, we propose strategies and guidelines for practitioners to keep different types of community members actively engaged in online co-creation and to manage sustainable innovation practice better.

Keywords: company-hosted online community; member; sustainable innovation; co-creation

\section{Introduction}


The concept of sustainable innovation (SI) has attracted the interest of researchers and practitioners due to increased concerns for global sustainability over the last decades (Caiado, de Freitas Dias, Mattos, Quelhas, \& Leal Filho, 2017; Rosca, Arnold, \& Bendul, 2017). The term SI refers to an advance of products or services improving economic performance with less externalities in the form of social hazards (Nielsen, Reisch, \& Thøgersen, 2016). SI entails the involvement of a wide range of people possessing different interests and broad capabilities (Kruger, Caiado, França, \& Quelhas, 2018; Liedtke, Baedeker, Hasselkuß, Rohn, \& Grinewitschus, 2015). Therefore, external sources of knowledge are the key to the SI process in which users are regarded as such a powerful source (Nielsen et al., 2016). Co-creation is an iterative process by bringing different parties together to jointly produce a mutually valued outcome (Kruger et al., 2018). As such, a co-creation practice can act as a strategy for pooling external knowledge and constructing pathways to sustainable future (Camacho-Otero, Boks, \& Pettersen, 2019; Nielsen et al., 2016).

Advanced digital technologies provide a variety of communication channels to engage knowledgeable but physically separate users (Fuger, Schimpf, Füller, \& Hutter, 2017; Hyysalo, Johnson, \& Juntunen, 2017). An increasing number of companies across industries have created and maintained Company-hosted Online Co-creation Communities (COCC) for individuals and companies that share common interests, a sense of belonging, and rules for participation and governance to communicate and collaborate online in order to put companies in a favorable, competitive position (Jeppesen \& Frederiksen, 2006; Piller, Ihl, \& Vossen, 2010; Rullani \& Haefliger, 2013). Sustainable product/service co-innovation is essential to COCC. In addition to injecting their personal experience into innovation, users also benefit other stakeholders by improving social or health conditions of a community or even the society as a whole (Nielsen et al., 2016). For example, companies in China increasingly engage in online consumer communities to facilitate sustainable user innovation. According to China 
Internet Watch ${ }^{1}$, a large number of online communities have been created and managed by companies and entrepreneurs in China, such as WeChat Group by Tencent and Huafen by Huawei. Those communities provide a variety of tools in support of communication among community members.

User participation is vital to the sustainability and timeliness of online co-creation (Kruger et al., 2018). Practice theory (Rullani \& Haefliger, 2013) suggests that core members of a community set the standards of excellence (quality, communication) through their non-material artifacts, which influence behaviors of other community members. Here core members are referred to as active members who frequently post in an online community (Chen, Cheng, and Liu 2008). To motivate user engagement and live up to social criteria, it is important for both practitioners and researchers to understand user behaviors and their contributions to COCC (Hyysalo et al., 2017; Jaakkola \& Alexander, 2014; Nielsen et al., 2016). In an online community, users in well-defined roles would facilitate communication, learning, knowledge exchange and the sustainability of an online community (Brown, 2001; Herrmann, Jahnke, \& Loser, 2004). There has been some prior research on the roles and motivations of community members. For example, Füller, Hutter, Hautz, and Matzler (2014) identified six member types in an innovation contest community, showing both cooperation and competition among community members. Johnson, Safadi, and Faraj (2015) found that community leaders made many positive and concise posts with simple languages familiar to other members. Lim and Kumar (2017) identified information, entertainment, and connectedness as motives for predicting one's commitment to a community. Benamar, Balague, and Ghassany (2017) proposed that core members would contribute to the creation and diffusion of individual activities as a social practice, in turn shaping the behavior of other members.

However, there are several limitations and gaps of the literature. First, many prior studies differentiated core members of a community from peripheral members largely

\footnotetext{
${ }^{1}$ https://www.chinainternetwatch.com/18994/online-community-2016/
} 
based on their posting frequencies (Edelman, 2007; Hojman \& Szeid, 2008; X. Zhang, Martin, \& Newman, 2015). Few studies have examined whether there are different types of core members in terms of what and how they contribute to a community, especially in a COCC context, as users' roles may vary depending on the purpose a community. Second, previous studies on motivations of users' participation in an online community mainly investigated motivational factors (Fernandes \& Remelhe, 2016; Hossain, 2012). There is a lack of evidence and understanding of potential differences in the participation and contributions of core community members with different motivations (Hyysalo et al., 2017; Nielsen et al., 2016). Third, it remains unclear how different types of core members may impact other members' behavior in a COCC (Rullani \& Haefliger, 2013).

To fill those research gaps, this research intends to answer the following research questions:

RQ1: What types of behaviors of core members can be found in a COCC?

RQ2: How do different types of core members of a COCC contribute to SI differently? RQ3: Do different types of core members of a COCC influence other members' engagement differently, and if so, how?

We deployed a three-phase approach to address those research questions. First, we performed a two-step cluster analysis to cluster members of a COCC automatically based on features of multiple behavior dimensions of individual members, including posting activities, the posted content, and social network status. A portion of members were then identified as core members. Second, based on Uses and Gratification Theory (UGT) (Dolan, Conduit, Fahy, \& Goodman, 2016), we developed a novel typology to further categorize core members based on three key aspects, including contribution type (e.g., innovative ideas, report of product problems, and solutions), target (e.g., product, community, or personal life), and individual orientation (e.g., socialization, venting emotions). Third, guided by Practice Theory (Rullani \& Haefliger, 2013), we explored how different types of core members may influence co-creation behavior of other community members. The results of the Kruskal-Wallis non-parametric test and 
pairwise comparisons revealed that different types of core members had different impacts on other members, which were reflected by the generated comments from the latter.

This research makes three important research contributions: 1) to our best knowledge, this research is the first effort to investigate behavioral differences of core members of a COCC; 2) by using UGT, this study discovered different types of core members of a COCC that may be driven by different informational or social motivations; and 3) this research extends the prior work of Rullani and Haefliger (2013) and Benamar et al. (2017) by investigating internal dynamics, showing that different types of core members had different impacts on the behavior of other community members in the community. The findings of this research also provide practical insights on how to improve user engagement and promote SI practice.

The rest of the paper will be organized as follows. First, Section 2 will review the related work on taxonomies of online community members, followed by the introduction to the research methodology in Section 3. Section 4 presents the results of data analytics. Then, the main findings and limitations of this study will be discussed in Section 5. Finally, the paper will be concluded with a summary of research contributions of this study in Section 6.

\section{Literature review}

2.1 Online company-hosted co-creation communities for SI

SI entails combining resources, knowledge, and capabilities from various stakeholders (Boons \& Lüdeke-Freund, 2013). Various forms of online co-creation communities have been created in support of idea sharing among community members, creating innovations collaboratively, and adoption of solutions by community members (Hyysalo et al., 2017). To improve a co-creation process, researchers have investigated online users' roles in different online communities, such as innovation-contest communities (Füller et al., 2014; Guo, Zheng, An, \& Peng, 2017; Moritz, Redlich, \& Wulfsberg, 2018), crowdsourcing communities (Fuger et al., 2017), and open source 
software communities (Barcomb, Kaufmann, Riehle, Stol, \& Fitzgerald, 2018; Crowston \& Shamshurin, 2017).

Those roles, in essence, are driven by personal experience and motivations of individual members with a product or a service (Nielsen et al., 2016). The full potential of sustainable co-creation remains under-explored (Nielsen et al., 2016). The adoption of COCCs is of great significance for a company to meet social criteria when pursuing sustainability (H.-H. Lee \& Dolen, 2015; Yang \& Li, 2016). Social sustainability means that organizations encourage participation and diversity, promote connectedness within and outside their community, ensure equity, and satisfy basic needs of stakeholders (K. Lee \& Jung, 2019). In a COCC, both customer-to-customer problem solving and customer-to-manager interactions are encouraged and the product development task assigned by managers to customers is given freely during a new idea generation process (Piller et al., 2010). For users who contribute to SI, their motivation is no longer personal needs, but the needs of stakeholders (Nielsen et al., 2016). Therefore, members of a COCC not only need to seek an advance in products and services for performance improvement, but also to meet social criteria (Nielsen et al., 2016). A better understanding of users' growing roles in SI would help companies better manage online co-creation communities for specific types of innovation.

Therefore, existing user types identified by previous studies are no longer applicable to the COCC context. This research seeks to advance the understanding of user roles in a specific COCC context.

\subsection{Taxonomies of online community members}

According to Welser, Gleave, Fisher, and Smith (2007), user types or roles in online settings can be defined based on quantitative, qualitative, and structural attributes of users. As a result, researchers have deployed three general methods for categorizing online community members, including quantitative, qualitative, and structural approaches: 
1) Qualitative approaches analyze context and content of communication generated by members of a community (Pfeil, Svangstu, Ang, \& Zaphiris, 2011). This interpretative method allows the identification and understanding of member behaviors and the meaning behind their interactions (Füller et al., 2014).

2) Quantitative approaches focus on examining the intensity of individual members' activities in an online community, such as the number of posts created and the number of stories shared in the community (Guo et al., 2017).

3) Structural approaches employ social network analysis to categorize member roles in an online community from data about member interactions in the community (Gleave, Welser, Lento, \& Smith, 2009). This approach provides a view of community structure (Burt, 2005).

It has been suggested that a single approach for discovering the types of online community members is insufficient (Fuger et al., 2017). Instead, an integrative approach that combines two or more approaches would be more appropriate, especially when the goal is to achieve a comprehensive understanding of fragmented, inconclusive, and equivocal phenomena like online communities (Venkatesh, Brown, $\&$ Sullivan, 2016). Some researchers have explored an integrated approach for different types of online communities (Akar, Mardikyan, \& Dalgic, 2019; Benamar et al., 2017; Fuger et al., 2017; Füller et al., 2014; Guo et al., 2017; Kou, Gray, Toombs, \& Adams, 2018; Pfeil et al., 2011). For example, Pfeil et al. (2011) investigated online support communities and summarized characteristics of member behavior through content analysis and structural equivalence. Kou et al. (2018) studied an online user experience community. By applying linguistic analysis of member posts and comments and social structures, they identified 6 member types (i.e., knowledge broker, translator, experienced practitioner, conversation facilitator, and learner). Guo et al. (2017) studied a crowdsourcing community during new product development. They defined five member types (i.e., project leader, active designer, generalist, communicator, passive designer, and observer). 
Individual core members have their own preferred topics, which will be reflected in their posts that attract different audience (Benamar et al., 2017). Therefore, core members may contribute differently to a community. However, there has been little research on identifying different types of core users in a COCC and their contributions to SI.

\subsection{The drivers of member participation}

Several studies have investigated motivations of members to participate in an online community based on Uses and Gratifications Theory (UGT). UGT posits that there are four types of benefits that individuals can derive from media usage (Katz et al., 1974), including cognitive benefits that relate to information acquisition and improvement of understanding of the environment; social integrative benefits that relate to strengthening one's ties with relevant others; personal integrative benefits that relate to strengthening the credibility, status, and confidence of an individual; and hedonic or affective benefits that enhance aesthetic or pleasurable experiences. For example, Whiting and Williams (2013) identified ten motives of individuals' participation in an online community, including contentedness, information seeking, pastime, entertainment, relaxation, expression of opinions, communication utility, convenience utility, information sharing, and knowledge about others.

Researchers also proposed three key dimensions related to consumer use of online communities, including process (entertainment), socialization, and content (information need) (Chen, Yang, \& Tang, 2013; F. Stafford, Royne, \& L. Schkade, 2004; Peters, H. Amato, \& R. Hollenbeck, 2007). Lim and Kumar (2017) identified information, incentives, entertainment, and connectedness as motives for one's commitment to a community, which, in turn, strengthens brand attachment.

\subsection{Influence of core members on other community members}

Practice Theory (Rullani \& Haefliger, 2013) is a theory of how social beings, with diverse motives and intentions, make and transform the world in which they live. It is a 
dialectic between a social structure and a human agency working back and forth in a dynamic relationship (Corsini, Laurenti, Meinherz, Appio, \& Mora, 2019). Researchers have explored how a community regulation that contains social rules and shared values is diffused and guides peripheral members to participate in a community (Corsini et al., 2019). When peripheral members read the posts and comments generated by core members, the former may be influenced by 'the footprint of the practice' contained in the content posted by the latter (Rullani \& Haefliger, 2013). This may lead to the adoption and socialization of practice standards and in turn promote common ways of innovation (Benamar et al., 2017).

Understanding how community leaders and their social interactions within a community may influence the performance of other community members is often recognized as needed future research in existing literature (Benamar et al., 2017; Xiao, Travis, \& Newman, 2014). Especially, in the field of COCC, there is a lack of empirical evidence about the influence of different types of core members on other members (Benamar et al., 2017).

\section{Methodology}

This study analyzed data collected from an online co-creation community, Huafen, hosted by Huawei Technologies, Co., Ltd. in China. Figure 1 shows the overall procedure of the study. First, through a two-step cluster analysis of individual members' activities, including making posts, comments, and likes, we identified core members of the community. Second, via analysis of posts and comments generated by the core members, we examined how different types of core members contributed to the community and SI. Finally, based on Practice Theory (Rullani \& Haefliger, 2013), we investigated potential influence of core members on other community members' contribution to SI from social network structure and activity perspectives. 


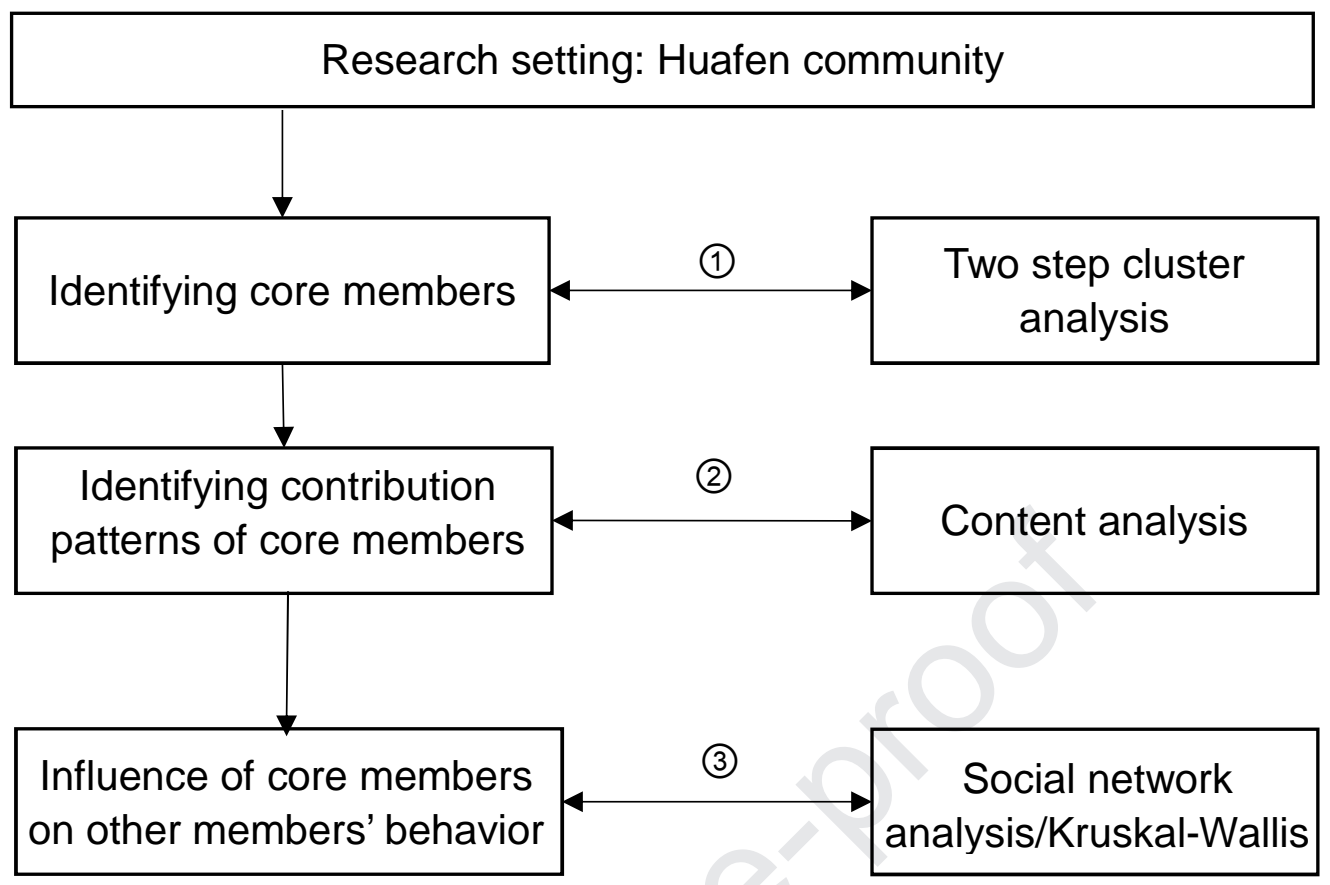

Figure 1. Research design

\subsection{Data collection}

We collected data from the Huafen online community (https://club.huawei.com/) in this study. Huafen is the official co-creation community created and hosted by Huawei Technologies, Co., Ltd for improving social sustainability. Huawei is a Chinese telecommunication equipment and consumer electronics manufacturer that produces a

wide range of products including smartphones, tablets, wearables, PCs, and broadband and home devices. It was ranked 72 th among the Fortune 500 companies in 2018. Huafen is aimed to distribute up-to-date information about Huawei products, provide solutions to consumers' problems, and enable consumers to exchange and share their Huawei product experience through interactive activities in the community. Huafen is also a platform for Huawei to gather consumers' opinions for improving their products and achieving growth of consumers and company simultaneously. At present, Huafen has more than 20 million registered members.

There are many product-series centered sub-communities in the Huafen 
community. We selected the sub-community associated with Huawei Mate20 smartphone series, which is the most active sub-community (i.e., with the largest number of members) in Huafen. We collected data from this sub-community generated between February 3rd and March 3rd, 2019. The data included 20,256 original posts generated by 13,248 non-manager community members, as well as 4,124 likes and 256,910 comments (i.e., responses). It is worth noting that the total number of posts and comments collected from that one-month period was close to 280,000 , which is sufficient for data analytics. In order to control the scope and complexity of this study, we did not collect more data. Some previous studies on roles or types of online community users also used similar short-term data or data with similar size (Akar et al., 2019; Bulgurcu, Osch, \& Kane, 2018). The proposed methodology should be generic and applicable to larger data size. As many previous studies, we assume that the behavior of community members should be relatively consistent over time.

\subsection{A three-phase procedure}

To answer the research questions, we performed a three-phase analysis on the collected data to discover core members of the Mate20 sub-community. First, we analyzed individual members' activities in the sub-community, including their posts, comments, and likes, to identify core members. Then, via analysis of those members' post and comment content, we explored which product-related issues different types of core members discussed to contribute to the co-creation process. Finally, through structural analysis, we investigated social positions of individual core members in the community according to their interactions with other community members.

\section{Identification of core members through clustering}

In the first phase, we aimed to identify core community members according to their activities in the community, which were assessed in three dimensions, including posts, 
comments, and likes, that would reflect members' participation levels (Teichmann, Stokburger-Sauer, Plank, and Strobl (2015)). Specifically, we performed a two-step cluster analysis that combined both hierarchical and non-hierarchical methods (Moritz et al., 2018). We first deployed a hierarchical clustering algorithm using the Ward's minimum variance method to determine the number of clusters $(k=4)$ for non-hierarchical clustering (Milligan \& Cooper, 1987), then used the k-means algorithm to cluster those community members into four clusters based on seven variables selected from literature (e.g., Benamar et al. 2017) and heuristics. Those seven variables included the number of original posts (i.e., a member's initiatives), the number of comments made, the number of received likes and comments (i.e., a member's influence on others), the average number of received comments per post (i.e., influence density), the average number of comments made per post (i.e., reaction density), the number of self-comments (i.e., the number of comments made on their own posts, indicating the degree of one's self-orientation), and the number of comments for community managers. At the end, we labelled the four generated clusters, with one of them being the core member cluster that consisted of 81 members who contributed 1,148 original posts and 13,362 comments during the data collection period. The detailed results will be reported in the results Section.

\section{Analysis of post and comment content}

After identifying core community members, we analyzed the content of 81 core members' posts and comments based on UGT to further categorize them into sub-categories in order to achieve a better understanding of their contributions to co-innovation at a finer granularity.

To understand the content generated by the core members, the posts and comments of individual core members were coded based on answers to two questions: 1) what was the objective of a particular post or comment? We primarily focused on cognitive 
benefit (i.e., information acquisition) and social integrative benefit (i.e., satisfying social need) of UGT; and 2) what was the main issue or topic discussed in the content (e.g., innovative idea about a product or experience with using a product)? Finally, we developed 12 coding themes (i.e., categories) and associated motivation labels (Table 2). Two independent coders coded the posts/comments individually and then converged. The Cohen's Kappa coefficient was 0.76 , indicating a strong agreement between the two coders (Landis \& Koch, 1977).

Table 2. The final coding schemes used for content analysis

\begin{tabular}{l}
\hline Contribution types \\
\hline 1- Product Innovation \\
1.1 Innovative, new ideas related to new \\
product design and product \\
improvement \\
1.2 Reporting product problems
\end{tabular}

1.3 Product usage advice and suggestions

1.4 Discuss or share other companies' competing products

Examples

"It is recommended to add a password when turning of the phone."

"Mate20X mobile phone, Bluetooth and Wifi conflict!"; "My phone consumes electricity significantly. How about yours?"

"Discover a new power saving setting!"

"Qualcomm and Huawei 5G baseband comparison."

"Mate20 Pro is my most satisfactory mobile phone due to its photo effect."

\section{2- Information sharing}

2.1 Personal stories about a product or product use

2.2 Advocating or Promoting other products of the same company

2.3 Sharing community norms and functionalities

"Today, I went to an after-sales store to change my phone."

"Huawei will launch a new product with curved surface soon."

"Community norm: The member level and required points in the Huafen club."

\section{3- Information seeking}

3.1 Questions about community life

"Is there an administrator? Is this picture against the community rule?"

3.2 How to solve a problem when using "My phone cannot get online. What a product happened?"

\section{4- Socialization}

4.1 Call for group purchase, common "Are any of you interested in group behavior purchase of Mate20 to get a better deal?"

4.2 Personal life (e.g., showing pictures "Using Huawei Mate20 Pro to record that one took with his/her phone) my daily life!" 
By following the prior work of Pfeil et al. (2011) and Benamar et al. (2017), we examined the difference ratio (in percentages) between a member's post and comment distribution across theme categories and the average distribution among all members for each category (Equation 1):

$$
\text { Difference ratio }=\frac{N_{m_{i j}}-\text { Mean }_{j}}{\text { Mean }_{j}}
$$

Where $\mathrm{Nm}_{\mathrm{ij}}$ represents the number of posts and comments made by the $\mathrm{i}_{\text {th }}$ member in the $\mathrm{j}_{\text {th }}$ theme category, while $\mathrm{Mean}_{\mathrm{j}}$ represents the average number of posts and comments made by all core members in the $\mathrm{j}_{\text {th }}$ category. By doing this, we were able to identify which theme categories each core member type contributed more (or less) than the average of core members based on difference ratio values.

\section{Influence of core members on other community members}

In this phase, by following the Practice Theory, we examined how different types of core members influenced other community members' contribution to co-creation from perspectives of social network structure and level of activities. First, we used Gephi, an open-source social network analysis and visualization software package, to build a social network for the community. In the network, each node represented a community member, while a link from node $\mathrm{A}$ to node $\mathrm{B}$ indicated that member $\mathrm{A}$ commented on a post or comment of B. Then, we calculated in-degree (i.e., the number of links coming into a node), out-degree (i.e., the number of outward links from a node), and betweenness degree (i.e., a measure of the extent to which the number of times a node acts as a bridge along the shortest path between two other nodes) of each core member (Prell, 2011). A node with a high betweenness degree indicates that a member plays an important role in knowledge transfer through the community. By using the HITS algorithm (Kleinberg, 1999), we measured authorities (i.e., the nodes that most of nodes point to) and hub (i.e., nodes that point to other nodes with high authorities) 
scores of nodes.

Second, the numbers of posted and received comments can reflect a member's influence on other community members. To investigate the influence of core members on other members and validate our clustering result, we ran a Kruskal-Wallis test on the numbers of posted and received comments by core members. In addition, a post hoc analysis after a Kruskal-Wallis test was performed to analyze pairwise group difference.

\section{Results}

\subsection{Identification of core community members through clustering}

Table 3 shows descriptive statistics of the measures of participation behavior of community members. Through cluster analysis, members of the Mate20 Series community were segmented into four clusters, including 11,113 lurkers, 1,919 visitors, 135 commentators, and 81 core members, as shown in Table 4. The average silhouette value, a measure of how similar an object is to its own cluster (cohesion) compared to other clusters, was 0.712 , indicating that the generated clusters were appropriate.

Table 3. Descriptive statistics of member activities within the community

\begin{tabular}{lrrrrc}
\hline Activity type & $\mathrm{N}$ & Mean & Std & Min & Max \\
\hline $\begin{array}{l}\text { PostNo: the \# of original posts made by a } \\
\text { member }\end{array}$ & 20,256 & 1.529 & 1.750 & 1 & 46 \\
$\begin{array}{l}\text { CommentNo: the \# of comments made } \\
\text { on others' posts or comments }\end{array}$ & 102,643 & 7.748 & 30.871 & 0 & 751 \\
$\begin{array}{l}\text { ReceivedCommentNo: the \# of } \\
\text { comments received from others for a } \\
\text { member }\end{array}$ & 154,267 & 11.645 & 30.111 & 0 & 761 \\
$\begin{array}{l}\text { LikeNo: \# of likes received from other } \\
\text { members }\end{array}$ & 4,124 & 0.311 & 2.429 & 0 & 189 \\
$\begin{array}{l}\text { Influence density: the \# of comments } \\
\text { received from other members per post }\end{array}$ & 85,862 & 6.481 & 12.647 & 0 & 386 \\
$\begin{array}{l}\text { Reaction density: the \# of comments } \\
\text { made on others' posts or comments per } \\
\text { post }\end{array}$ & 50,277 & 3.795 & 11.072 & 0 & 261.5
\end{tabular}


Manager-oriented comments: the \# of comments on a manager's posts

Self-oriented comments: the number of comments on one's own post(s)

$\begin{array}{lllll}15,626 & 1.179 & 4.0534 & 0 & 207\end{array}$

Note: $\mathrm{N}$ represents sample size; Std represents standard deviation; Min and Max denote the minimum and maximum value of an activity

Table 4. Interactive activities of different types of community members (average value per member)

\begin{tabular}{lcccc}
\hline Activities & $\begin{array}{c}\text { Lurkers } \\
(11,113)\end{array}$ & $\begin{array}{c}\text { Visitors } \\
(1,919)\end{array}$ & $\begin{array}{c}\text { Comm- } \\
\text { entators } \\
(135)\end{array}$ & $\begin{array}{c}\text { Core } \\
(81)\end{array}$ \\
\hline Average PostNo & 1.21 & 2.73 & 2.88 & 14.17 \\
CommentNo & 2.68 & 18.77 & 173.71 & 164.96 \\
Percentage of self-oriented comments & $10.0 \%$ & $9.92 \%$ & $12.4 \%$ & $10.6 \%$ \\
Percentage of manager-oriented comments & $2.72 \%$ & $2.10 \%$ & $1.97 \%$ & $0.7 \%$ \\
ReceivedCommentNo & 3.98 & 43.39 & 34.27 & 272.62 \\
LikeNo & 0.14 & 1.02 & 0.65 & 6.09 \\
Influence density & 3.16 & 23.44 & 12.96 & 49.43 \\
Reaction density & 2.14 & 7.55 & 79.17 & 16.12 \\
\hline
\end{tabular}

Among the four clusters, the largest cluster is the lurker group, which is consistent with the findings of previous research (e.g.,Crowston \& Shamshurin, 2017; Füller, Matzler, \& Hoppe, 2008; Ridings, Gefen, \& Arinze, 2006). Lurkers generated the fewest posts and received fewer comments from other community members but were more prone to comment on managers' posts than other types of members. Commentators, on average, made more comments on others' posts or comments and were characterized by the strongest reaction density. Visitors generated a similar number of posts as commentators, but made fewer comments on other members' posts or on their own posts. Core members, despite being a small portion of the community, contributed the majority of posts, and received the largest number of comments, and also made the second largest number of comments on other members' posts or 
comments. Last but not least, Table 5 shows that community members who generated fewer posts were more willing to participate in the activity initiated by the company, while core members preferred to initiate their own topics.

Table 5. Categorization of core members based on difference ratios (\%)

\begin{tabular}{|c|c|c|c|c|c|c|c|c|}
\hline Content Themes & 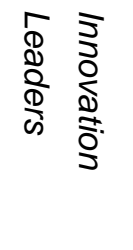 & 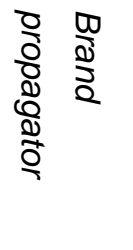 & $\begin{array}{l}\frac{0}{0} \\
\vdots \\
\vdots \\
\vdots \\
5 \\
\vdots \\
0 \\
0\end{array}$ & 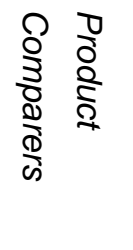 & 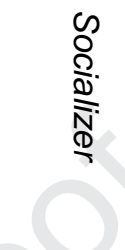 & 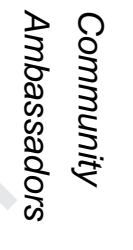 & 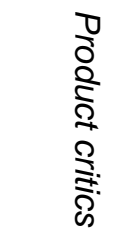 & 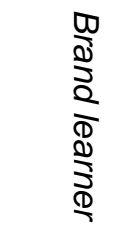 \\
\hline $\begin{array}{l}\text { Innovative ideas related to } \\
\text { new product design }\end{array}$ & 348.62 & -59.50 & -76.86 & -76.86 & -79.75 & -100 & -87.54 & -2.80 \\
\hline Problem report & 38.46 & -100 & -74.29 & -74.29 & 35.00 & -80.71 & 163.08 & -22 \\
\hline $\begin{array}{l}\text { Advocating other products } \\
\text { of the company }\end{array}$ & 60.22 & 420.71 & -66.94 & -0.82 & -42.14 & -33.88 & -10.99 & -69.14 \\
\hline $\begin{array}{l}\text { Product usage advice and } \\
\text { suggestions }\end{array}$ & 94.07 & -0.41 & -14.64 & 4.33 & -66.80 & -14.64 & -13.18 & -15.90 \\
\hline $\begin{array}{l}\text { Socialization (e.g., group } \\
\text { purchase) }\end{array}$ & 57.74 & -74.37 & 46.47 & 17.18 & 117.88 & -85.35 & -60.56 & 9.37 \\
\hline Personal life & -23.93 & 276.74 & 391.11 & -73.09 & -58.79 & -56.27 & -71.02 & -56.05 \\
\hline $\begin{array}{l}\text { Personal feelings about a } \\
\text { product }\end{array}$ & 89.92 & -35.03 & -44.31 & 17.57 & -2.54 & -78.34 & 56.60 & -30.70 \\
\hline $\begin{array}{l}\text { Personal stories about a } \\
\text { product or its use }\end{array}$ & 43.79 & -82.69 & -40.66 & 28.57 & -13.46 & -75.27 & 1.18 & 66.15 \\
\hline $\begin{array}{l}\text { Information seeking } \\
\text { related to product use }\end{array}$ & 51.63 & -73.12 & -59.04 & -7.84 & 65.76 & -92.32 & 15.79 & 43.36 \\
\hline $\begin{array}{l}\text { Discuss or share other } \\
\text { companies' products }\end{array}$ & 60.22 & 131.43 & -66.94 & 230.61 & 6.07 & -66.94 & -40.66 & -69.14 \\
\hline $\begin{array}{l}\text { Questions about } \\
\text { community life }\end{array}$ & 24.62 & -100 & -100 & 15.71 & 1.25 & -100 & 86.92 & 62 \\
\hline $\begin{array}{l}\text { Sharing community norms } \\
\text { and functionality }\end{array}$ & -10.99 & -100 & 65.31 & -100 & -100 & 313.27 & -100 & -100 \\
\hline
\end{tabular}

\subsection{Different types of core members and their contributions to the community}

To understand what exactly the core members contributed to the co-creation community, we probed into different types of core members. We manfully coded the posts and comments generated by the core members. Specifically, we first examined the difference ratios (i.e., Equation 1) of the 12 themes shown in Table 2 between 
every core member's generated content vs. the average content of all core members. Then, we clustered the core members based on their difference ratios into 8 core member categories, then calculated the mean of difference ratios of all members in each theme for every core member category, which are presented in Table 5. For example, the value of $348.62 \%$ at the intersection of "Innovation Leaders" and "Innovative ideas" indicates that on average, the average number of product innovation ideas contributed by the core members in the "Innovation Leaders" category was $348.62 \%$ more than the average number of innovation ideas contributed by all core members.

Based on the differences in contributions, we categorized core members into the following eight groups, including:

1) Innovation leaders (13 members) played a leadership role in product innovation in the co-creation community. They were featured by contributing a dominant number of posts and comments related to product innovation, including those on new product ideas, product problems, product usage suggestions, and information about products of competitors, which can enable Huawei to incorporate innovative ideas into future product design and improve product quality to better meet consumer needs. They were the drivers of co-innovation. The following are examples of posts from innovation leaders:

"In short, I would recommend to add a password when turning off a phone so that in case the phone is stolen, I can still trace its location..."

"I think the phone should add a function that can display the battery level..."

2) Brand Propagators (4 members) were eager to promote Huawei products. For example, they liked to share new product information in the community, and were also interested in keeping track of other products of Huawei's competitors. In the 
meanwhile, those members also actively engaged in socialization activities such as sharing their personal life in the community. The following is an example of posts made by brand propagators:

"Recently, four new Huawei products received the $3 C$ certificates from the National Quality Certification Center. They are very likely to be the P30 series that Huawei will release next month..."

3) The 7 core members in the product-in-life category emphasized the use of a product in their personal life, such as sharing the pictures taken by their phone. They did not often share knowledge about products or seeking for information, but they were willing to engage in discussions about community norms and functionalities. Two examples of posts made by such members are as follows:

"The most beautiful travel - with the Mate20 to visit the Forbidden City in Beijing ..." "I used my Mate20 to record the first day of work in the Chinese new year ..."

4) Product comparers (7 members) are characterized by high expectations of products. They like to compare products of other competing manufacturers in the market against Huawei's products and provide performance and cost comparisons (see examples below). They not only seek for others' opinions about differences among different manufacturers' products, but also share their own perspectives about which product seems superior. Therefore, their contributions to the community enable Huawei to have a better and timely understanding of the pros and cons of its products in comparison to competitors' products from a consumer perspective.

“Xiaomi 9 vs Huawei Mate20 Pro in side-by-side photos ..."

"Can someone tell me about the experience of using XR Series vs. Samsung S9? ...” 
5) Socializers' (8 members) main focus was to socialize with other community members. Their posts/comments were mostly oriented to all other community members but less likely to be related to product innovation, such as:

"Please complete a survey: do you buy broken-screen insurance and

$$
\text { extended warranty?...” }
$$

6) Community ambassadors (14 members) were those who were concerned about issues regarding community norms and regulations. In addition, similar to innovation leaders, they offered product usage advice and suggestions. For example:

"Set up HuaweiShare in ten easy steps, and say goodbye to the data line..."

7) Product critics (13 members) were essential to product innovation. Those members were vocal about problems of products or their feelings (e.g., dissatisfaction) experienced when using products. Therefore, they were keen to product quality improvement. For example,

"Where is the picture I just downloaded? Sometimes looking for a picture on this phone is really difficult and frustrating..."

8) Brand learners (15 members) were members who were relatively new to products and lack of sufficient product knowledge. Therefore, they often made posts to share their personal stories about a product or product use, hoping to get some feedback or confirmation, or sought for information or knowledge about product use from the community. For example:

"Can I ask a question: Can the Mate20p original headset be used to answer the phone?...”

Among the above core member categories, innovation leaders, product comparers, and product critics (approximately $41 \%$ of all core members) can be considered as the major source for contributing to SI in the co-creation community through their posts 
and comments on various product-related issues, which can provide insights and ideas to manufacturers for future product design and quality improvement. Those three types of innovation-driven core members focused on different yet complementary issues related to products. For example, innovative leaders mainly concentrated on new ideas for products, while product critics focused on reporting problems and sharing their emotions about products.

\subsection{Influence of different types of core members on other members' contribution to}

\section{innovation co-creation}

\subsubsection{Social network structure}

We calculated several centrality measures of the community network as described in Section 3.2. As shown in Figure 2, the innovation leaders possessed the highest indegree and outdegree, indicating that they were highly followed by other members in the community. The innovation leaders not only made the most innovation related posts and comments than any other types of core members, but also received more follow up comments from other community members, showing that innovation leaders indeed played a key role in innovation.

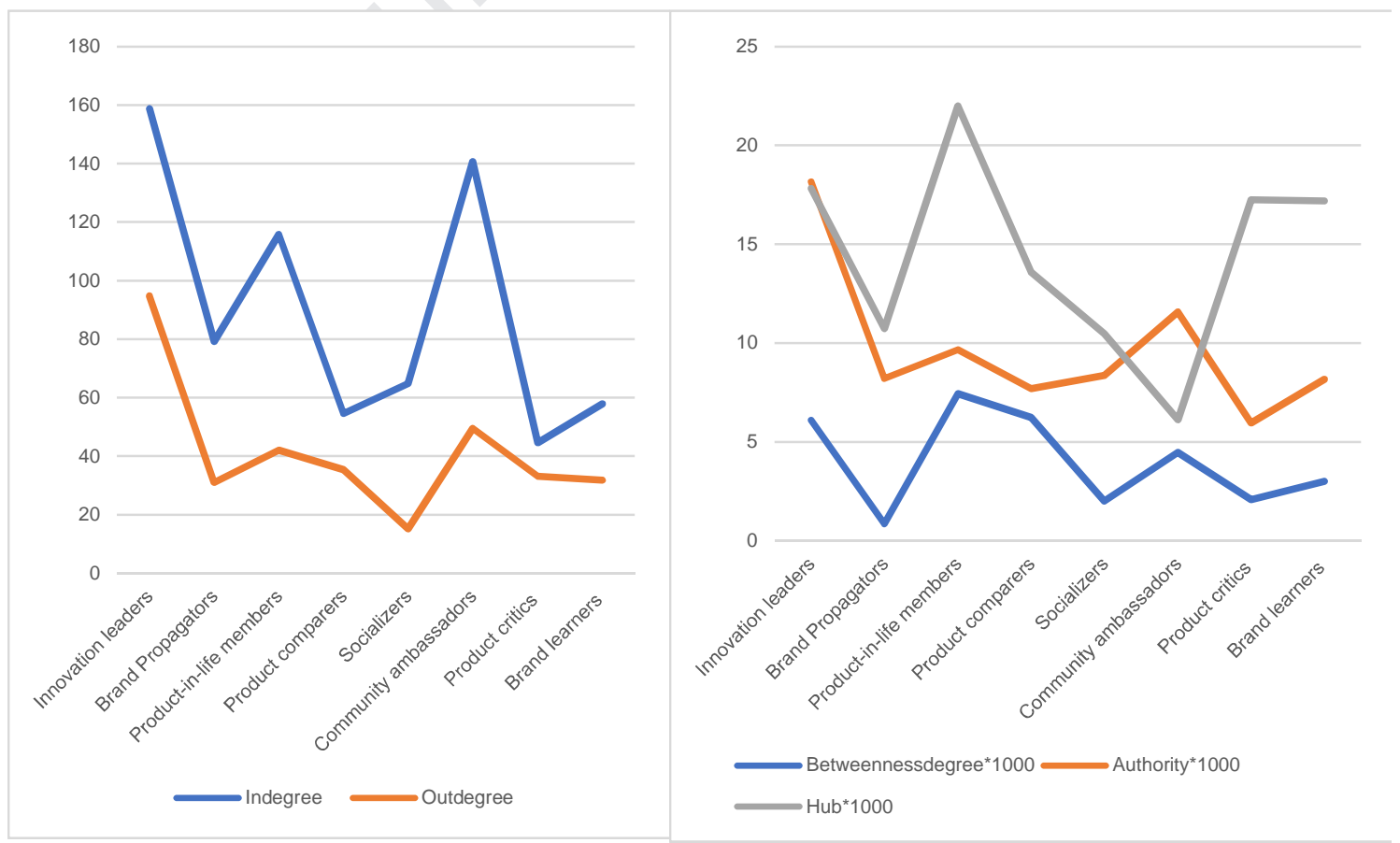


Figure2. Community network centrality measures of different core members

While community ambassadors ranked the second in terms of indegree, they were characterized by a relatively low outdegree. In contrast, product critics had the lowest indegree and a relatively low betweenness degree, indicating that the problems they reported did not receive many comments from other members. There might be multiple reasons for this phenomenon. For example, some problems may not be perceived as problems, or not have been experienced, by other members. The product-in-life members, because of the high betweenness score, can be viewed as community gatekeepers, while socializers, surprisingly, had the second lowest betweenness score.

In general, the innovation leaders and community ambassadors seem to have the largest impact on other members' behaviors in the community, which is manifested by the significantly higher indegree scores than other types of core members.

\subsubsection{Activities of core members}

It is common that peripheral members of online communities tend to generate content infrequently (Crowston \& Shamshurin, 2017; Gong, Lim, \& Zhu, 2015; Perna, Interdonato, \& Tagarelli, 2018). Because different types of core members have different motivations and concentrate on different issues, their behaviors in a community may vary as well, which may exert different influence on other members.

Previous research has suggested to use the number of received comments as an indicator of one's influence in an online community (de Vries, Gensler, \& Leeflang, 2012; Pletikosa Cvijikj \& Michahelles, 2013). The activity of making a comment by a core member can be perceived as calling for reciprocity (Pai \& Tsai, 2016; Zheng, Li, $\mathrm{Wu}, \& \mathrm{Xu}, 2014)$, which can facilitate knowledge sharing. According to Pesämaa, Pieper, Vinhas da Silva, Black, and Hair (2013), the willingness to share knowledge is moderated by self-efficacy and community receptivity and can enhance personal interactions and benefit community cohesion. It is widely recognized that knowledge sharing is a kind of prosocial behavior (Ray, Kim, \& Morris, 2014). Once other 
members see valuable posts and comments from core members, they will feel gratified and likely provide comments in return (Yang \& Li, 2016).

Drawing on previous literature and the context of this study, for each type of core members, we used the number of comments received from other members and the number of comments made on other members' posts as measures of their influence on other members' activities (Table 6). The larger the number of comments on a core member's post, the more significant the influence of that member on the rest of the community.

Using RStudio, we first conducted a Shapiro-Wilk test to check the distributions of the number of comments made on other members' posts $(\mathrm{W}=0.824, \mathrm{P}<0.001)$ and the number of comments received from other members $(\mathrm{W}=0.87, \mathrm{P}<0.05)$. Due to their non-normal distributions and the small and different size of each core member group, we performed a Krsukal-Wallis non-parametric test to examine whether there existed significant differences in the numbers of received comments from other members and from different core member groups. Results showed a positive effect of the numbers of received comments from other members $\left(\chi^{2}(7)=29.233, p<0.001\right)$ and comments made on other members' posts $\left(\chi^{2}(7)=14.203, \mathrm{p}<0.05\right)$.

Table 6. Impact of core members

\begin{tabular}{lcccc}
\hline & $\begin{array}{r}\text { \# of Comments made on other } \\
\text { members' posts }\end{array}$ & $\begin{array}{r}\text { \# of comments received from } \\
\text { other members }\end{array}$ \\
\cline { 2 - 5 } & Mean & Standard deviation & Mean & $\begin{array}{c}\text { Standard } \\
\text { deviation }\end{array}$ \\
\hline Innovation leaders & 233.00 & 247.39 & 419.69 & 212.20 \\
Brand Propagators & 166.00 & 173.07 & 335.00 & 89.83 \\
Product-in-life members & 203.86 & 148.64 & 218.43 & 103.07 \\
Product comparers & 133.71 & 102.48 & 225.57 & 132.29 \\
Socializers & 75.25 & 66.48 & 214.00 & 79.28 \\
Comm. ambassadors & 110.64 & 196.68 & 364.64 & 129.21 \\
Product critics & 185.62 & 116.81 & 209.00 & 89.23
\end{tabular}


Then we ran a pair-comparison test to examine whether the three types of core members who mainly focused on innovation (i.e., innovation leaders, product comparers, and product critics) differed from other types of core members who paid less attention to innovation (i.e., brand propagators, product-in-life members, brand learners, community ambassadors, and socializers). For the sake of simplicity, we refer to the other five categories of core members who paid less attention to innovation as "other contributors". There were significantly more comments from other members on innovation leaders' posts than on those of product comparers $(\mathrm{p}<.05)$, product critics $(\mathrm{p}<.05)$, and other contributors $(\mathrm{p}<.05)$, implying that innovation leaders had higher influence on other members than other three groups. On the other hand, product critics, product comparers $(\mathrm{p}=\mathrm{n} . \mathrm{s}$.$) , and other contributors received similar$ numbers of comments from others (Table 7). In addition, there were no significant differences in the numbers of comments made on other members' posts or comments among those groups.

Table 7. Pairwise comparisons of the numbers of comments received

\begin{tabular}{lc}
\hline Pairwise comparisons (group 1 - group 2) & Mean differences \\
\hline Innovation leaders - Other contributors & $162.817^{* *}$ \\
Innovation leaders - Product comparers & $194.121^{* *}$ \\
Innovation leaders - Product critics & $210.692^{* *}$ \\
Product comparers - Other contributors & -31.303 \\
Product critics - Other contributors & -47.875 \\
Product critics - Product comparers & -16.571 \\
\hline
\end{tabular}
$* *: p<0.01$

\section{Discussion}

\subsection{Major findings}

The main objective of this study is to explore different behaviors of core members in an online co-creation community, as well as differences in their contributions to 
social concerns and in their impact on the behavior of other members in the community, which has never been investigated before. To achieve those goals, we conducted a three-phase approach guided by UGT and Practice Theory that integrated analysis of posting activities, content posted, and community network structure. By using the real-world data collected from the Huafen online community in China, we first found that core members were more dependent on other community members and in some cases had little connection with the host company compared to other members who generated fewer messages. Then, we identified 8 types of core members that concentrated on different issues motivated by different interests. The developed typology includes innovation leaders, brand propagators, product-in-life members, product comparers, socializers, community ambassadors, product critics, and brand learners (see Table 5). Among them, innovation leaders, product comparers, and product critics are considered the major contributors to the SI process. They often took initiatives in making posts on product-related issues. In the meantime, their posts and comments also incurred more follow-up comments from other community members. So, they not only led the SI process, but also influenced other community members. The analysis also revealed that different core members had different impact on other members. For example, the average number of comments made by other committee members on innovation leaders' posts was significantly larger than that of other non-innovation types of core members (i.e., brand propagators, product-in-life members, brand learners, community ambassadors and socializers). Meanwhile, we also found that innovation leaders received significantly more comments from other members than product critics and product comparers. However, the members belonging to product critics and product compare categories received nearly the similar numbers of comments from other members, meaning that they had similar impact on other members. These results together demonstrate that different types of core members, in particular those who focus on SI, exert different impacts on other members' contribution to community.

Several prior studies have analyzed the behavior of online community members 
(Akar et al., 2019; Benamar et al., 2017; Fuger et al., 2017; Füller et al., 2014; Guo et al., 2017; Kou et al., 2018; Pfeil et al., 2011) and found similarities across different research contexts (Fuger et al., 2017). The question about whether a company-hosted online co-creation community focusing on SI appears to have different member types arises. This study categorizes core members in the context of COCC. Previous literature defined a leadership role in co-innovation as project leader (Guo et al., 2017), collaborator (Fuger et al., 2017), or master (Füller et al., 2014), who shares his expertise and interacts actively with other community members, but never distinguished innovation leaders, product comparers, and product critics according to innovation types. The innovation leaders possess novel ideas and focus on potential needs of other community members. The product critics can be compared to incremental user innovation type, identified by Nielsen et al. (2016), who seek to improve the existing products or services(e.g. energy efficiency). Product comparers participate in the SI process in a unique way by sharing and comparing information about products of other competitors in the same industry. They not only serve as a bridge connecting with other communities in the society, but also drive the participation of other members as well. We predict that the product comparers' unique behavioral patterns strongly relate to the COCC context. Socializers' main focus is mostly oriented to socialization but less likely related to innovation. Surprisingly, different from socializers identified by Füller et al. (2014) and Akar et al. (2019) and conversation facilitator identified by (Kou et al., 2018), in the COCC context, socializers only interact with others at a moderate level. In contrast, the members in the product-in-life category who emphasize the use of a product in their personal life are of special value for a community because their high betweenness degree improves social sustainability of the community. Brand learners are members who are relatively new to products and lack of sufficient product knowledge. Community ambassadors are members who tend to be concerned about issues regarding community norms and regulations, as well as product usage suggestions. They focus on potential needs of other community members. The Brand Propagators category, which has never been found in literature, is eager to 
share product information in the community. Those members interact and submit ideas at a minimum level among all the core members. Most core members participated in all activities within COCC context.

\subsection{Limitations and future research}

This study bears some limitations that offer future research opportunities. First, participation of co-creation community members is a major pre-determinant of a SI process. However, SI may also be affected by other factors such as platform construction and knowledge diffusion (Kruger et al., 2018). In our study, we only investigated core member types in sustainable innovation. Future research could integrate our results with other relevant factors to build a holistic model for SI. Second, given the scope and complexity of this study, we only collected data from a single online co-creation community owned by one Chinese company. It would be beneficial if future studies could validate the findings and methodology of this research by using data collected from other online co-creation communities. Third, this study focuses on co-creation in China. Research has shown that cultures have influence on individuals' behavior in a group environment (D. Zhang, Lowry, Zhou, \& Fu, 2007). It would be essential to investigate if community members with different cultural backgrounds may be more likely to be a certain type of core member.

\section{Conclusion}

Different from those of often-mentioned crowdsourcing communities, members of a COCC aim to not only help with product and service improvement, but also meet social needs as well. This paper highlights the importance of core member investigation to improving the sustainability of online communities. Practitioners would also benefit from analyzing and understanding the behavior of core members by using an integrated approach that includes identifying member roles through their activities, shared content and social position in a community.

From an academic perspective, this research makes three novel research 
contributions. First, literature has shown that an online community typically consists of a small but active member group and a larger number of passive, peripheral members (Fuller, Jawecki, \& Muhlbacher, 2007; Toral, Martínez-Torres, \& Barrero, 2010; Ye \& Kishida, 2003). Most of previous studies focused on differences between core and peripheral members. Little is known about different types of core members and whether they contribute to co-creation of innovation differently. This research categorizes core members of a COCC through clustering analysis, then proposes a method that relies on a set of coding schemes developed based on UGT and the distance ratio measure to develop a novel topology for core members of COCC. Second, the developed typology consists of 8 types of core members. Furthermore, we identify the types of core members that are co-innovation oriented, achieving a deeper understanding of core members in an online COCC context. A key difference between our proposed typology and topologies proposed by previous studies lies in that the former focuses on categorization of core members in terms of their relevance and importance to innovation co-creation, whereas the latter focus on general categorization of all members of a community. For example, previous research has never defined innovation leaders, product comparers, and product critics from other core members. We also predict that product comparers, socializers, and brand propagators are strongly related to the COCC context due to their unique behavioral patterns. Third, this study extends previous work by providing a new perspective of internal dynamics of a COCC through investigating the influence of different types of core members on other members on the basis of Practice Theory. Specifically, we used the number of follow-up comments on core members' posts as a measure of their impact on other members. The results show that different types of core members would have varying levels of influence on other members, which has never been studied in the literature.

From a practitioner's perspective, the findings of this research also provide a number of practical implications that can help companies improve their capabilities of sustainable innovation through company-hosted online co-creation communities. They may consider offering incentives and recognition to those innovation leaders who 
generate the best and/or most innovation ideas that benefit new product design and to product critics who identify critical flaws or problems of products that lead to product quality improvement; support product-in-life members to demonstrate the better use of products in their daily life, or provide better, richer communication tools in their online community that enable socializers and community ambassadors to maximize their roles in keeping the community cohesive and interactive, and/or ask brand learners to help develop a product Q\&A session that can benefit other new consumers. Finally, the resources of SI not only come from customers, but also from competitors and other stakeholders (Boons \& Lüdeke-Freund, 2013). Therefore, a co-creation community should not censor or discourage product comparers as their posts may help manufacturers identify the relative pros and cons of their own products in comparison to competitors and look for solutions to address those cons.

Company-hosted online co-creation communities are increasingly popular nowadays as a promising platform for companies to connect with their users or consumers, advertise their new products, allow consumers to provide peer support, and more importantly, provide a venue for involving consumers in the co-innovation process so that products can be continuously innovated.

\section{Acknowledgements}

This research was partially supported by the National Natural Science Foundation of China under Grant Nos. 71772075、71672074, the Social Science Foundation of Guangzhou, China under Grant No. 2018GZYB31.

\section{Reference}

Akar, E., Mardikyan, S., \& Dalgic, T. (2019). User Roles in Online Communities and Their Moderating Effect on Online Community Usage Intention: An Integrated Approach. International Journal of Human-Computer Interaction, 35(6), 495-509.

Barcomb, A., Kaufmann, A., Riehle, D., Stol, K.-J., \& Fitzgerald, B. (2018). Uncovering the Periphery: A Qualitative Survey of Episodic Volunteering in Free/Libre and Open Source Software Communities. International Journal of Human-Computer Interaction. doi:10.1109/TSE.2018.2872713 
Benamar, L., Balague, C., \& Ghassany, M. (2017). The Identification and Influence of Social Roles in a Social Media Product Community. Journal of Computer-Mediated Communication, 22(6), 337-362.

Boons, F., \& Lüdeke-Freund, F. (2013). Business models for sustainable innovation: state-of-the-art and steps towards a research agenda. Journal of Cleaner Production, 45, 9-19.

Brown, R. (2001). Group Processes: Dynamics Within and Between Groups.

Bulgurcu, B., Osch, W. V., \& Kane, G. C. (2018). The Rise of the Promoters: User Classes and Contribution Patterns in Enterprise Social Media. Journal of Management Information Systems, 35(2), 610-646.

Burt, R. S. (2005). Brokerage and closure: An introduction to social capital: Oxford university press.

Caiado, R. G. G., de Freitas Dias, R., Mattos, L. V., Quelhas, O. L. G., \& Leal Filho, W. (2017). Towards sustainable development through the perspective of eco-efficiency-A systematic literature review. Journal of Cleaner Production, 165, 890-904.

Camacho-Otero, J., Boks, C., \& Pettersen, I. N. (2019). User acceptance and adoption of circular offerings in the fashion sector: Insights from user-generated online reviews. Journal of Cleaner Production, 231, 928-939.

Chen, G. L., Yang, S. C., \& Tang, S. M. (2013). Sense of virtual community and knowledge contribution in a P3 virtual community: Motivation and experience. Internet Research, 23(1), 4-26.

Corsini, F., Laurenti, R., Meinherz, F., Appio, F., \& Mora, L. (2019). The Advent of Practice Theories in Research on Sustainable Consumption: Past, Current and Future Directions of the Field. Sustainability, 11(2), 1-19.

Crowston, K., \& Shamshurin, I. (2017). Core-periphery communication and the success of free/libre open source software projects. Journal of Internet Services \& Applications, 8.

de Vries, L., Gensler, S., \& Leeflang, P. S. H. (2012). Popularity of Brand Posts on Brand Fan Pages: An Investigation of the Effects of Social Media Marketing. Journal of Interactive Marketing, 26(2), 83-91.

Dolan, R., Conduit, J., Fahy, J., \& Goodman, S. (2016). Social media engagement behaviour: a uses and gratifications perspective. Journal of Strategic Marketing, 24(3-4), 261-277.

Edelman, D. C. (2007). From the periphery to the core: As online strategy becomes overall strategy, marketing organizations and agencies will never be the same. Journal of Advertising Research, 47(2), 130-134.

F. Stafford, T., Royne, M., \& L. Schkade, L. (2004). Determining Uses and Gratifications for the Internet. Decision sciences, 35, 259-288.

Fernandes, T., \& Remelhe, P. (2016). How to engage customers in co-creation: customers' motivations for collaborative innovation. Journal of Strategic Marketing, 24(3-4), 311-326.

Fuger, S., Schimpf, R., Füller, J., \& Hutter, K. (2017). User roles and team structures in a crowdsourcing community for international development-a social network 
perspective. Information Technology for Development, 23(3), 438-462.

Füller, J., Hutter, K., Hautz, J., \& Matzler, K. (2014). User Roles and Contributions in Innovation-Contest Communities. Journal of Management Information Systems, 31(1), 273-308.

Fuller, J., Jawecki, G., \& Muhlbacher, H. (2007). Innovation creation by online basketball communities. Journal of Business Research, 60(1), 60-71.

Füller, J., Matzler, K., \& Hoppe, M. (2008). Brand community members as a source of innovation. Journal of Product Innovation Management, 25(6), 608-619.

Gleave, E., Welser, H. T., Lento, T. M., \& Smith, M. A. (2009, 5-8 Jan. 2009). A Conceptual and Operational Definition of 'Social Role' in Online Community. Paper presented at the 2009 42nd Hawaii International Conference on System Sciences.

Gong, W., Lim, E. P., \& Zhu, F. (2015). Characterizing Silent Users in Social Media Communities. Paper presented at the Ninth International AAAI Conference on Web and Social Media.

Guo, W., Zheng, Q., An, W., \& Peng, W. (2017). User roles and contributions during the new product development process in collaborative innovation communities. Applied ergonomics, 63, 106-114.

Herrmann, T., Jahnke, I., \& Loser, K.-U. (2004). The Role Concept as a Basis for Designing Community Systems. Paper presented at the Cooperative Systems Design, Pp 163-178, Ios.

Hojman, D. A., \& Szeid, A. (2008). Core and periphery in networks. Journal of Economic Theory, 139(1), 295-309.

Hossain, M. (2012). Crowdsourcing: Activities, incentives and users' motivations to participate. Paper presented at the 2012 International Conference on Innovation Management and Technology Research.

Hyysalo, S., Johnson, M., \& Juntunen, J. K. (2017). The diffusion of consumer innovation in sustainable energy technologies. Journal of Cleaner Production, 162, S70-S82.

Jaakkola, E., \& Alexander, M. (2014). The Role of Customer Engagement Behavior in Value Co-Creation: A Service System Perspective. Journal of Service Research, 17(3), 247-261.

Jeppesen, L., \& Frederiksen, L. (2006). Why Do Users Contribute to Firm-Hosted User Communities? The Case of Computer-Controlled Music Instruments. Organization Science, 17(1), 45-63.

Johnson, S., Safadi, H., \& Faraj, S. (2015). The Emergence of Online Community Leadership. Information Systems Research, 26, 165-187.

Kleinberg, J. M. (1999). Authoritative sources in a hyperlinked environment. Journal of the ACM (JACM), 46(5), 604-632.

Kou, Y., Gray, C., Toombs, A., \& Adams, R. (2018). Understanding Social Roles in an Online Community of Volatile Practice: A Study of User Experience Practitioners on Reddit. ACM Transactions on Social Computing, 1(4), 17.

Kruger, C., Caiado, R. G. G., França, S. L. B., \& Quelhas, O. L. G. (2018). A holistic model integrating value co-creation methodologies towards the sustainable 
development. Journal of Cleaner Production, 191, 400-416.

Landis, J. R., \& Koch, G. G. (1977). The measurement of observer agreement for categorical data. Biometrics, 33(1), 159-174.

Lee, H.-H., \& Dolen, W. (2015). Creative Participation: Collective Sentiment in Online Co-Creation Communities. Information \& Management, 52. doi:10.1016/j.im.2015.07.002

Lee, K., \& Jung, H. (2019). Dynamic Semantic Network Analysis for Identifying the Concept and Scope of Social Sustainability. Journal of Cleaner Production, 233. doi:10.1016/j.jclepro.2019.05.390

Liedtke, C., Baedeker, C., Hasselkuß, M., Rohn, H., \& Grinewitschus, V. (2015). User-integrated innovation in Sustainable LivingLabs: an experimental infrastructure for researching and developing sustainable product service systems. Journal of Cleaner Production, 97, 106-116.

Lim, H., \& Kumar, A. (2017). Variations in consumers' use of brand online social networking: A uses and gratifications approach. Journal of Retailing \& Consumer Services, S0969698917303259.

Milligan, G. W., \& Cooper, M. C. (1987). Methodology Review: Clustering Methods. Applied Psychological Measurement, 11(4), 329-354.

Moritz, M., Redlich, T., \& Wulfsberg, J. (2018). Who Are Your Design Heroes? Exploring User Roles in a Co-creation Community. Paper presented at the World Conference on Information Systems \& Technologies.

Nielsen, K. R., Reisch, L. A., \& Thøgersen, J. (2016). Sustainable user innovation from a policy perspective: A systematic literature review. Journal of Cleaner Production, 133, 65-77.

Pai, P. Y., \& Tsai, H. T. (2016). Reciprocity norms and information-sharing behavior in online consumption communities: An empirical investigation of antecedents and moderators. Information \& Management, 53(1), 38-52.

Perna, D., Interdonato, R., \& Tagarelli, A. (2018). Learning to lurker rank: an evaluation of learning-to-rank methods for lurking behavior analysis. Social Network Analysis and Mining, 8(1), 39.

Pesämaa, O., Pieper, T., Vinhas da Silva, R., Black, W. C., \& Hair, J. F. (2013). Trust and reciprocity in building inter-personal and inter-organizational commitment in small business co-operatives. Journal of Co-operative Organization and Management, 1(2), 81-92.

Peters, C., H. Amato, C., \& R. Hollenbeck, C. (2007). An Exploratory Investigation of Consumers' Perceptions of Wireless Advertising. Journal of Advertising, 36, 129-145.

Pfeil, U., Svangstu, K., Ang, C. S., \& Zaphiris, P. (2011). Social Roles in an Online Support Community for Older People. International Journal of Human-Computer Interaction, 27(4), 323-347.

Piller, F., Ihl, C., \& Vossen, A. (2010). A typology of customer co-creation in the innovation process. Social Science Electronic Publishing.

Pletikosa Cvijikj, I., \& Michahelles, F. (2013). Online engagement factors on Facebook brand pages. Social Network Analysis and Mining, 3(4), 843-861. 
Prell, C. (2011). Social Network Analysis: History, Theory and Methodology.

Ray, S., Kim, S. S., \& Morris, J. G. (2014). The Central Role of Engagement in Online Communities. Information Systems Research, 25(3), 528-546.

Ridings, C., Gefen, D., \& Arinze, B. (2006). Psychological barriers: Lurker and poster motivation and behavior in online communities. Communications of the association for Information Systems, 18(1), 16.

Rosca, E., Arnold, M., \& Bendul, J. C. (2017). Business models for sustainable innovation-an empirical analysis of frugal products and services. Journal of Cleaner Production, 162, S133-S145.

Rullani, F., \& Haefliger, S. (2013). The periphery on stage: The intra-organizational dynamics in online communities of creation. Research Policy, 42(4), 941-953.

Teichmann, K., Stokburger-Sauer, N. E., Plank, A., \& Strobl, A. (2015). Motivational Drivers of Content Contribution to Company-Versus Consumer-Hosted Online Communities. Psychology \& Marketing, 32(3), 341-355.

Toral, S. L., Martínez-Torres, M. d. R., \& Barrero, F. (2010). Analysis of virtual communities supporting OSS projects using social network analysis. Information and Software Technology, 52(3), 296-303.

Venkatesh, V., Brown, S. A., \& Sullivan, Y. W. (2016). Guidelines for Conducting Mixed-methods Research: An Extension and Illustration. Journal of the Association for Information Systems, 17(7), 435-494.

Welser, H., Gleave, E., Fisher, D., \& Smith, M. (2007). Visualizing the Signatures of Social Roles in Online Discussion Groups. Journal of social structure, 8(2), $1-31$.

Whiting, A., \& Williams, D. (2013). Why people use social media: a uses and gratifications approach. Qualitative Market Research, 16(4), 362-369(368).

Xiao, Z., Travis, M., \& Newman, M. E. J. (2014). Identification of core-periphery structure in networks. Physical Review E Statistical Nonlinear \& Soft Matter Physics, 91(3), 784321-784321-784310.

Yang, X., \& Li, G. X. (2016). Factors influencing the popularity of customer-generated content in a company-hosted online co-creation community: A social capital perspective. Computers in Human Behavior, 64, 760-768.

Ye, Y., \& Kishida, K. (2003). Toward an understanding of the motivation Open Source Software developers. Paper presented at the Proceedings of the 25th international conference on software engineering.

Zhang, D., Lowry, P. B., Zhou, L., \& Fu, X. (2007). The Impact of Individualism-Collectivism, Social Presence, and Group Diversity on Group Decision Making Under Majority Influence. Journal of Management Information Systems, 23(4), 53-80.

Zhang, X., Martin, T., \& Newman, M. E. (2015). Identification of core-periphery structure in networks. Physical Review E Statistical Nonlinear \& Soft Matter Physics, 91(3), 032803.

Zheng, H. C., Li, D. H., Wu, J., \& Xu, Y. (2014). The role of multidimensional social capital in crowdfunding: A comparative study in China and US. Information \& Management, 51(4), 488-496. 
Highlights:

- A three-step approach is proposed for innovation assessment

- There are eight types of core members motivated by different interests

- Three types of core members are unique to the sustainable innovation context

- Innovation-oriented core members exert greater impacts on social condition of the community 


\section{Declaration of interests}

$\bigotimes$ The authors declare that they have no known competing financial interests or personal relationships that could have appeared to influence the work reported in this paper.

$\square$ The authors declare the following financial interests/personal relationships which may be considered as potential competing interests: 